\title{
Human dignity central to economic development
}

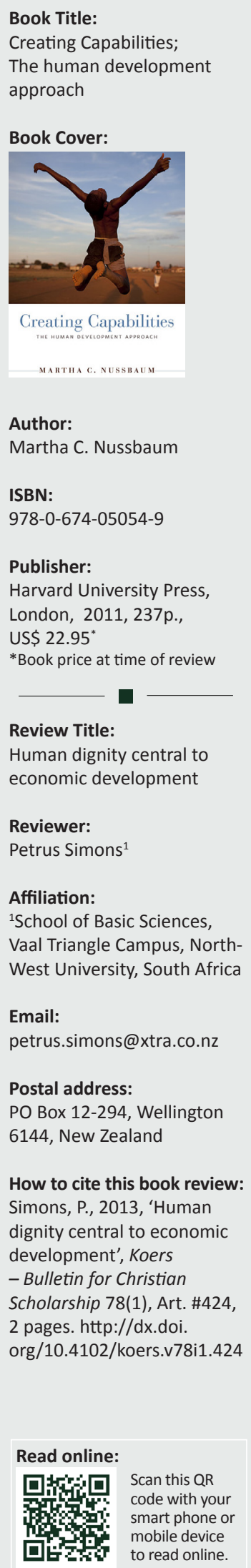

Martha Nussbaum asks a fundamental question: what is a life worthy of human dignity? Can any nation (states, including members of federations) be satisfied that all of its inhabitants, regardless of gender, race, wealth or education, are capable of living such a life? Since none of them could answer affirmatively, they are all regarded as developing nations.

But how should we objectively establish the extent to which people are able to lead a life worthy of human dignity? Is it possible to measure quality of life with regard to an ideal state? Nussbaum argues that the most important elements of people's quality of life cannot be reduced to a single metric without distortion. The Real Gross Domestic Product (GDP) per head of the population would be such a flawed indicator, since it masks inequality, discrimination, and poverty.

Nussbaum asks simply: what is each person able to do and to be? Each person should be appreciated as an end (Kant). This is the gist of her capabilities approach. Can one be educated adequately? Is medical care available to all? Are jobs available to all who are well educated? Capability failures due to discrimination and marginalisation occur frequently. Importantly, internal capabilities such as education should be combined with others to make them effective (jobs commensurate with one's education). Nussbaum proposes 10 central capabilities, with for each a threshold level, an essential to a life worthy of human dignity. They are:

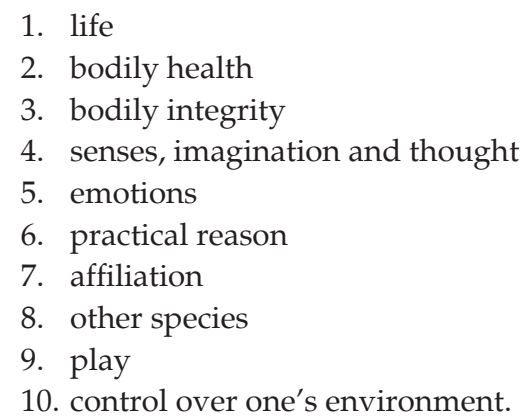

Governments should seek to lift their populations above all 10 thresholds. To establish the merits of this approach Nussbaum checks it against other approaches such as real GDP per capita, resources available, and human development indices. Most suffer from aggregation problems.

Nussbaum believes that the central capabilities should form a basis for fundamental political entitlements or a minimally just society (marked by political liberalism). The 10 capabilities can be politically justified on the basis of Socratic ethical debate and Aristotle's concept of the citystate.

How about cultural differences between nations? Nussbaum argues that the central capabilities apply cross-culturally. Human rights, for instance, existed in India already before colonisation. Anyway, the nation should be the institution to implement the approach because of its unified structure and constitution. A lack of social justice impedes the achievement of the ten capabilities in most nations. This indicates human vulnerability as an Aristotelian motivation for the capabilities approach. To achieve a good level of capabilities progressive taxation, for instance, is called for.

Clearly, once a capability is secured it should either remain so or be improved further. This is a challenge in its own right.

It is not only humans who should be entitled to a dignified life. Animals too should be protected against suffering. In this respect the disaggregated consideration of effects on all parts of human lives is important. Pursuing economic growth without considering the effects on the health of 
present and future generations, the environment and animal welfare is very inappropriate. People and their ability to function should matter ultimately. Their development should take centre-stage.

There is much to admire and appreciate in Nussbaum's approach. The 10 central capabilities are essential to ensure that all people are able to function in their proper vocation (as a Lutheran prayer puts it). Governments should document the capabilities of their citizens and find ways to lift and remove impediments.

Nussbaum's objections to economic growth as an indicator of human development are very much to the point. However, she does acknowledge insufficiently that economic growth represents a major ideology of ever greater progress through technology, competition et cetra. Many countries are happy to collect and publish data on human development as a sideshow, whilst putting their faith in the power of markets to raise the rate of economic growth. By the same token one is prepared to phase out inadequate housing or nasty ways of treating animals, but only as soon as we can afford it.

Nussbaum's reliance on Aristotle is significant, because his political philosophy is based on the polis, a small city-state. If we are to break free from the ideology of economic growth with its emphasis on competing in world markets, and acceptance of gross inequalities, then, we should move to small-scale local economic units that offer the best prospects for creating central human capabilities within a national political framework.

In principle, Nussbaum's approach is a very radical one. It deserves close attention and action on the part of political leaders. 